\title{
Mutual ownership: privatisation under a different name?
}

\author{
Will taking NHS providers out of state ownership and giving them to their employees to manage be \\ a charger to the rescue, or a Trojan horse for private equity?
}

\author{
Martin McKee professor of European public health, London School of Hygiene and Tropical Medicine, \\ London WC1H 9SH, UK
}

\begin{abstract}
What is to be done with the NHS in England? By common consent, the coalition government's reforms have failed to achieve their stated objectives-perhaps because their complex, largely incomprehensible design made it impossible for them to succeed. ${ }^{1}$ True, GPs were supposed to be in the driving seat, but in reality they are driving away from the NHS to an early retirement as they leave in droves. ${ }^{2}$ So what is the answer?
\end{abstract}

The latest "solution" to appear on the scene is mutualisation. This is the idea that NHS providers would be privatised (although its advocates seem reluctant to use that word) by being taken out of state ownership and managed by their employees. Politicians, such as the Cabinet Office minister Francis Maude, are promoting them enthusiastically, ${ }^{3}$ dropping hints that this could be the future of all current NHS provision after a Conservative victory in 2015. They draw encouragement from a recent report chaired by Chris Ham, of the King's Fund, that reviews the extensive and unsurprising evidence that employee engagement brings many benefits. It also shows that many, although not all, existing NHS providers already achieve high levels of engagement.

Levels are very slightly higher in mutual organisations that provide services to the NHS than in foundation trusts $(0.06$ points on a five point scale, although with no indication of whether this is statistically significant). However, the report's actual recommendations have conveyed nothing like as much enthusiasm as that of the politicians who have drawn on it. The report merely suggests that NHS providers should have greater freedom to test mutualisation, although those of a suspicious nature might recall that similar language was used in relation to foundation trusts not so long ago.

The idea of mutualisation can be superficially attractive, and a few mutual organisations have very high reputations. Strikingly, though, the list of enduring successes rarely seems to extend beyond John Lewis and Arup. Indeed, the good reputation of the former has been hijacked to create the misleading term "John Lewis-style" - as applied to Circle Health, the operator of
Hinchingbrooke Hospital, in which employees hold a minority stake but the real power lies with a group of hedge funds. ${ }^{5}$

Yet there is one problem that none of those advocating mutuals seems willing to tackle: how do you ensure that they remain mutuals-and what happens if they change their status? A collective amnesia seems to exist about the many other companies that went badly wrong after they were demutualised. This somewhat inglorious roll-call includes Northern Rock and Bradford and Bingley, whose reckless behaviour contributed to the financial crisis; and the Automobile Association, whose reputation plummeted after its new private equity owners cut costs, increased its debt, and eventually walked away with $£ 2$ bn (€2.5bn; $\$ 3.3 \mathrm{bn}$ ) in profit. $^{6}$

As these examples show, the journey to mutualisation, either by accident or design, could simply be the first step towards being swallowed up by a major corporation-one that is interested not in the care of patients, but rather in arranging its accounting practices to maximise profits and minimise its tax bill. The example of Southern Cross - a care home provider that collapsed after its scheme to sell and then lease back its facilities went badly wrong, causing severe anxiety to thousands of elderly and vulnerable residents and their families-should serve as a warning of what could happen if a chain of what are now NHS hospitals followed the same path.

Can we learn lessons from other countries where mutuals do play a greater role in healthcare, such as Germany, with its social insurance systems? The crucial difference is that mutual status in Germany is underpinned by legal safeguards, and employee representation is achieved by involving the trade unions, whose role as social partners is also enshrined in law. Consequently, it is inconceivable that a German social insurance fund could be taken over by a private equity firm based in an overseas tax haven. But a mutually owned hospital in England would enjoy no such protection. If those politicians arguing for mutual status believe that it should not be simply a stepping stone to 
corporatisation, then it is incumbent on them to put in place a similarly protective legal framework.

Continental European countries may also have something to teach us about employee engagement. German companies have two tier boards that exercise management and supervisory functions; and employees, who are represented mainly by their trade unions, have statutory membership of the latter. As the political economist Will Hutton and others have noted, this model of "Rhineland capitalism" has been much more successful in creating sustainable growth than the much less regulated model in the United Kingdom. ${ }^{7}$ Crucially, it shows that employee engagement can be achieved without changing ownership.

Once again, the debate on the future of the NHS in England seems characterised by taking an axiom with which few will disagree, whether it be "putting patients first" or "increasing employee engagement," and then moving rapidly to a proposed solution, such as the Health and Social Care Act—or, in this case, mutual ownership — without the usual intermediate step of diagnosing what the problem actually is.

Few people would disagree with the need to improve employee engagement. But, in the absence of adequate legal safeguards, it seems somewhat foolhardy to rush rapidly into a model of ownership that might be achieved in other ways, but which could easily lead to NHS providers being stripped of assets by private equity companies sheltering from taxation, and public scrutiny, on tropical islands.

\section{Competing interests: None declared.}

Provenance and peer review: Not commissioned; not externally peer reviewed.

\section{McKee M. Does anyone understand the government's plan for the NHS? BMJ} 2012;344:e399.

2 Rimmer A. Six in 10 GPs are considering early retirement, BMA survey finds. BMJ Careers 2014. http://careers.bmj.com/careers/advice/view-article.html?id=20016882.

3 Mason R. Hand hospitals over to their staff, says Francis Maude. Guardian 29 July 2014. www.theguardian.com/society/2014/jul/29/nhs-hospitals-hand-over-mutuals-francis-maude. King's Fund. Improving NHS care by engaging staff and devolving decision making: report of the review of staff engagement and empowerment in the NHS. 15 July 2014. www. kingsfund.org.uk/publications/articles/improving-nhs-care-engaging-staff-and-devolvingdecision-making.

5 McKee M. Circle Health is not like the John Lewis Partnership. BMJ 2011;343:d7897.

6 Wachman R. A sorry Saga at the AA? 1 July 2007. www.theguardian.com/business/2007/ jul/01/privateequity.observerbusiness.

7 Hutton W. The state we're in: why Britain is in crisis and how to overcome it. Vintage, 1996.

Cite this as: BMJ 2014;349:95150

(c) BMJ Publishing Group Ltd 2014 